\title{
Advanced Echocardiographic Assessment of Ebstein Anomaly in Children
}

\author{
Iolanda Muntean ${ }^{1,2}$, Asmaa Carla Barmou'², Rodica Togănel1,2 \\ 1 University of Medicine, Pharmacy, Science and Technology, Târgu Mureș, Romania \\ 2 Clinic of Pediatric Cardiology, Emergency Institute of Cardiovascular Diseases and Transplantation, Târgu Mureș, Romania
}

\section{CORRESPONDENCE \\ Iolanda Muntean \\ Str. Gheorghe Marinescu nr. 50 \\ 540136 Târgu Mureș, Romania \\ Tel: +40 744372276 \\ E-mail: iolanda.muntean@gmail.com}

\section{ARTICLE HISTORY}

Received: November 30, 2019

Accepted: December 19, 2019

Asmaa Carla Barmou • Str. Gheorghe Marinescu nr. 50, 540136 Târgu Mureș, Romania. Tel: +40 265216 368, E-mail: asmaa.carla@yahoo.com

Rodica Togănel • Str. Gheorghe Marinescu nr. 38, 540139 Târgu Mureș, Romania. Tel: +40 265215 551,

E-mail: rodicatoganel@yahoo.com
We describe the case of a 4-year-old female patient, diagnosed with Ebstein anomaly at the age of 1 year, who presented progressive deterioration of physical exercise capacity and failure to thrive. The physical examination revealed a $4 / 6$ grade holosystolic murmur, the $\mathrm{BMI}$ was at 3.7 percentile, and $\mathrm{SaO}_{2}$ was $90 \%$ on room air. The remainder of the physical examination was unimportant. The chest X-ray showed right sided chamber enlargement.

We have performed a complex echocardiographic assessment with an Epiq 7 (Philips Medical Systems) ultrasound system using an X5-1 xMatrix array transducer. The $2 \mathrm{D}$ echocardiogram revealed a dilated right atrium (RA) and right ventricle $(R V)$ with dilation of the tricuspid annulus $(35.9 \mathrm{~mm}, \mathrm{z}=2.92)$, and mild atrialization of the RV due to an abnormal tricuspid valve. The apical fourchamber image demonstrated tethering of the tricuspid septal leaflet to the ventricular septum, with a $24.3 \mathrm{~mm} / \mathrm{m}^{2}$ displacement index. The anterior leaflet was large, redundant, "sail-like", with dense attachments to the RV free wall. The left ventricle and atrium were slightly compressed by the volume overload in the right heart. There was a foramen ovale with a bidirectional shunt. We have traced the chamber areas (Figure 1A). According to the Carpentier classification, this was a type A Ebstein anomaly, with an adequate true RV volume. ${ }^{1}$ We have also calculated the Great Ormond Street Echocardiogram (GOSE) score, defined as the ratio between the combined RA area ( $\mathrm{RA}+$ atrialized RV) to that of the functional RV area + left atrium area + left ventricular area, at end-diastole, in apical four-chamber view. ${ }^{2}$ The GOSE score was 0.85 (grade II) in our patient. Color Doppler examination revealed a severe tricuspid regurgitation (Figure 1B).

Speckle-tracking analysis of the RV free wall demonstrated a well-functioning $\mathrm{RV}$, with a free wall strain of about $-19.6 \%$, with the following segmental strain values: basal $-19 \%$, mid $-18 \%$, apical $-22 \%$ (Figure 1C).

We have also performed a 3D echocardiographic assessment of the tricuspid valve (Figure 2). The multiplanar reconstruction data and the $3 \mathrm{D}$ enface view of the tricuspid valve from ventricular perspective demonstrated a small, rudimentary septal leaflet(s) besides the interventricular septum (Figure 2-s) and a 


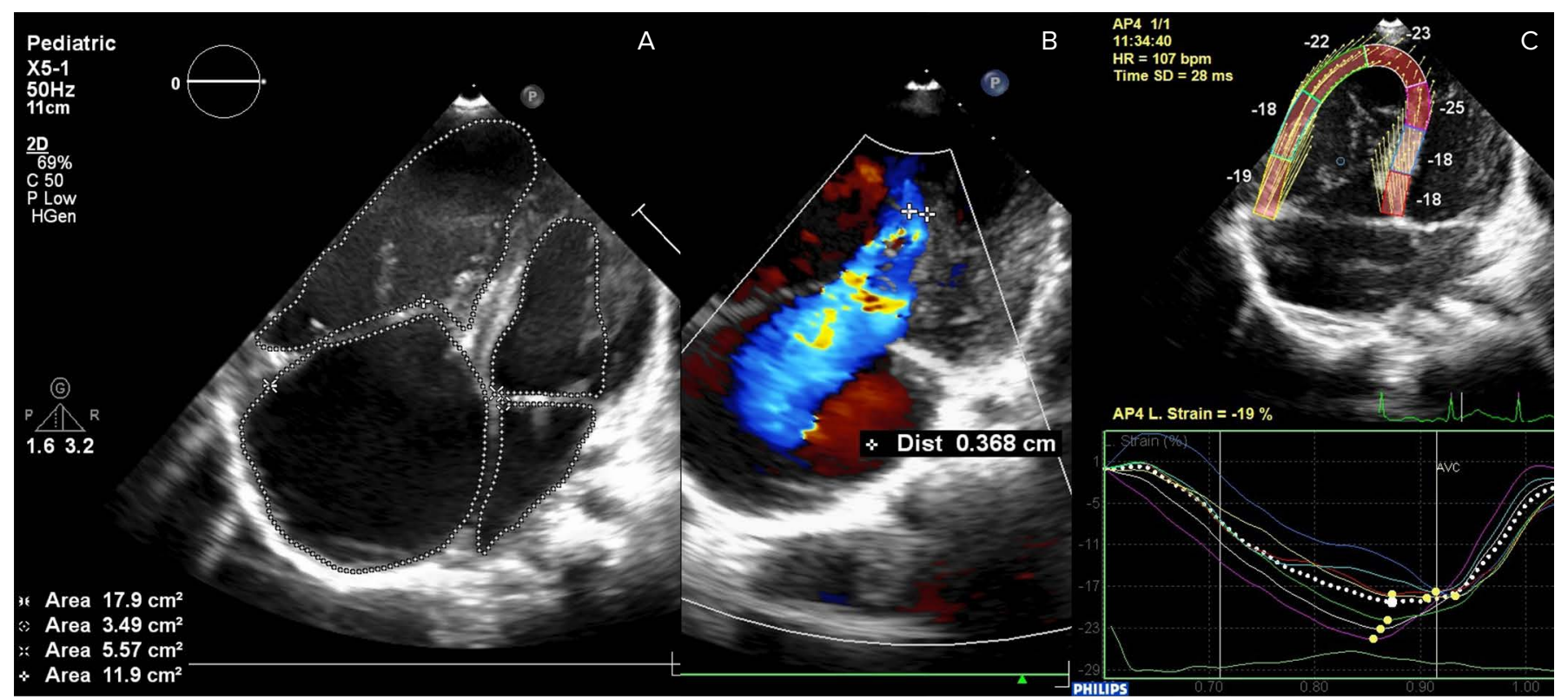

FIGURE 1. A - Apical four-chamber echocardiographic view with traced chamber areas, showing dilated right chambers. B - Color Doppler examination revealed a severe tricuspid regurgitation. C - Speckle-tracking analysis of the RV free wall demonstrated a wellfunctioning RV, with a free wall strain of about $-19.6 \%$.

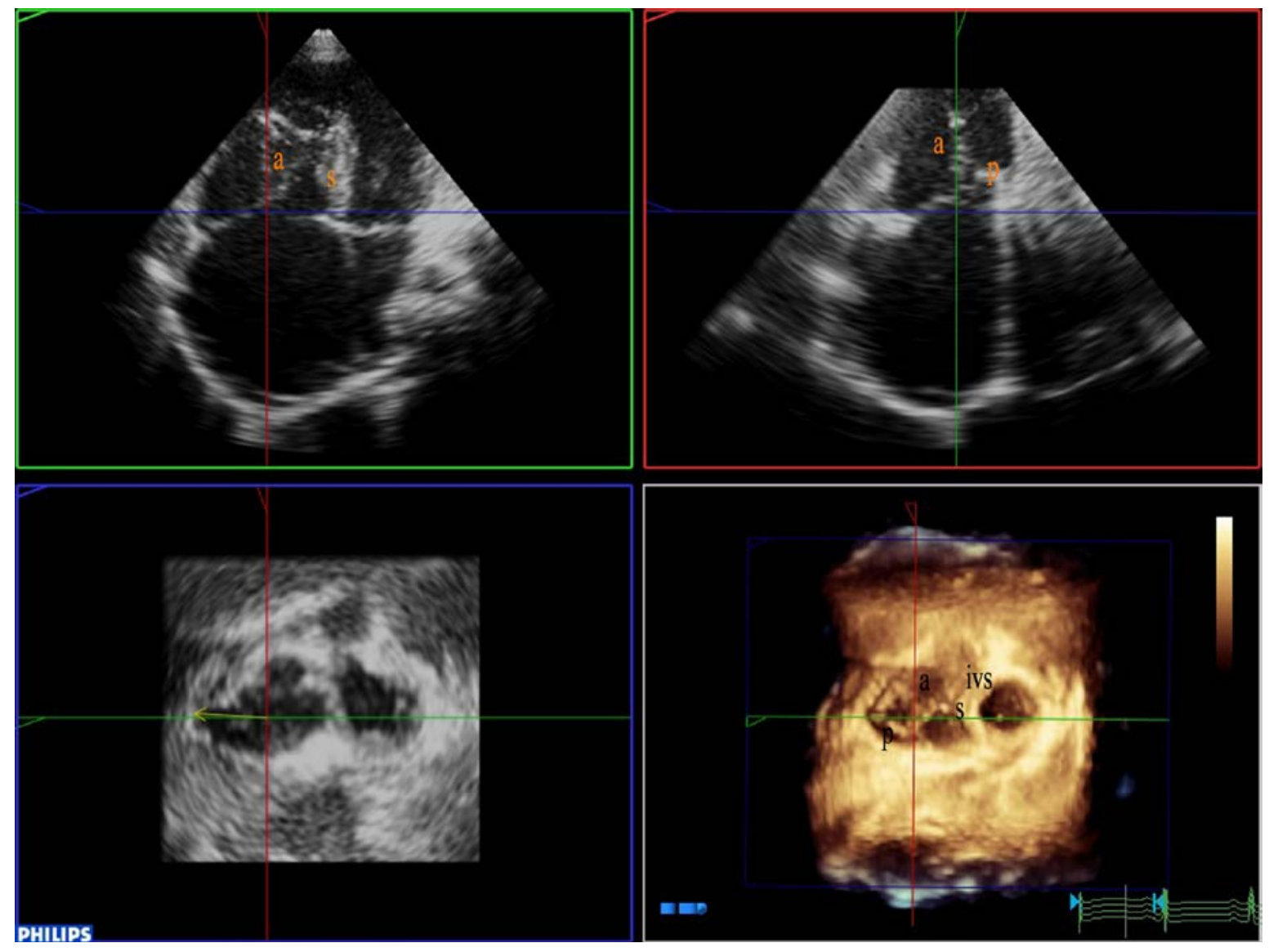

FIGURE 2. Multiplanar reconstruction data and the 3D enface view of the tricuspid valve from ventricular perspective with a rudimentary septal leaflet(s) besides the interventricular septum (s) and a large, sail-like anterior leaflet (a), with slight coaptation, visible on the corresponding four-chamber view, and also a small, tethered posterior leaflet ( $p$ ), with poor coaptation between the posterior (p) and septal leaflet (s) on three dimensional display. 
large, sail-like anterior leaflet (Figure 2-a), with slight coaptation, visible on the corresponding four-chamber view, and also a small, tethered posterior leaflet (Figure 2-p), with poor coaptation between the posterior ( $p$ ) and septal leaflet (s) on 3D display.

Three-dimensional echocardiography complements the conventional echocardiographic (2D and color Doppler) assessment of the TV in Ebstein anomaly. ${ }^{3-6}$ It allows a better description of leaflet morphology and spatial geometry of the tricuspid valve in this particular disease and thus can lead to a more effective management or surgical technique. Also, deformation imaging is useful in the assessment of the myocardial function of the RV. ${ }^{7}$

\section{CONFLICT OF INTEREST}

The authors declare no conflict of interests.

\section{REFERENCES}

1. Clair DG, Beach JM. Mesenteric ischemia. N Engl J Med. 2016;374:959968.

2. Oderich GS, Gloviczki P, Bower TC. Open Surgical Treatment for Chronic Mesenteric Ischemia in the Endovascular Era: When It is Necessary and What it is the Preferred Technique? Semin Vasc Surg. 2010;23:36-46.

3. Oliva IB, Davarpanah AH, Rybicki FJ, et al. ACR appropriateness criteria imaging of mesenteric ischemia. Abdom Imaging. 2013;38:714-719.

4. White CJ. Chronic Mesenteric Ischemia: Diagnosis and Management. Progress in Cardiovascular Diseases. 2011;54:36-40.

5. Hagspiel KD, Flors L, Hanley M, Norton PT. Computed Tomography Angiography and Magnetic Resonance Angiography Imaging of the Mesenteric Vasculature. Tech Vasc Interventional Rad. 2015;18:2-13.

6. Cai W, Li X, Shu C, et al. Comparison of Clinical Outcomes of Endovascular Versus Open Vascularization for Chronic Mesenteric Ischemia: A Metaanalysis. Ann Vasc Surg. 2015;29:934-940.

7. Oderich GS, Bower TC, Sullivan TM, Bjarnason H, Cha S, Gloviczki P. Open versus endovascular revascularization for chronic mesenteric ischemia: Risk-stratified outcomes. J Vasc Surg. 2009;49:1472-1479.

8. Kruger AJ, Walker PJ, Foster WJ, Jenkins JS, Boyne NS, Jenkins J. Open surgery for atherosclerotic chronic mesenteric ischemia. J Vasc Surg. 2007:46:941-945 